Check for updates

Cite this: RSC Adv., 2018, 8, 10541

\title{
Ozonation of ketoprofen with nitrate in aquatic environments: kinetics, pathways, and toxicity
}

\author{
Yongqin Zeng,,$^{\mathrm{a}}$ Xiaoxuan Lin, $\dagger^{\mathrm{a}}$ Fuhua Li, ${ }^{\mathrm{b}}$ Ping Chen, ${ }^{\mathrm{c}}$ Qingqing Kong, ${ }^{\mathrm{d}}$ \\ Guoguang Liu (D) *a and Wenying Lv ${ }^{a}$
}

In this study, nitrate ion $\left(\mathrm{NO}_{3}{ }^{-}\right)$was found to collaborate with ozone thereby accelerating the degradation of ketoprofen. $\mathrm{NO}_{3}{ }^{-}$was discovered to induce the generation of hydroxyl radicals $(\cdot \mathrm{OH})$, which was crucial to the decomposition of PPCPs in wastewater treatment plants. Kinetic studies on the decomposition of ketoprofen were investigated under different concentrations of $\mathrm{NO}_{3}{ }^{-}$. The impact mechanisms and degradation by-products were experimentally determined. The results revealed that all reactions fitted the pseudo-first-order kinetic model well. The presence of $\mathrm{NO}_{3}{ }^{-}$had the capacity to accelerate the ozonation of ketoprofen. The reaction by-products were evaluated by UPLC-Q-TOF-MS, and a total of five intermediates generated via the ozonation of ketoprofen were assessed. The transformation pathways were concluded to be hydroxylation, nitration, and debenzophenone and ketonized reactions. Additionally, the toxicity of the by-products was evaluated by employing Chlorella and Daphnia magna.

Received 29th November 2017 Accepted 13th February 2018

DOI: 10.1039/c7ra12894k

rsc.li/rsc-advances

Moreover, Cao found that the maximum concentration of ketoprofen in the Zhangweinanyun River system was $31.35 \mathrm{ng} \mathrm{\textrm {L } ^ { - 1 } , 5 , 6}$ whereas concentrations in the Yuecheng Reservoir ranged from 1.33 to $8.40 \mathrm{ng} \mathrm{L}^{-1}$. Additionally, the expanding aging "Baby boomer" population and improving quality of life worldwide means that overall consumption of ketoprofen is likely to increase over the next few years. ${ }^{7}$ Nevertheless, such adducts are difficult to effectively remove via conventional drinking water treatment processes including filtration, sedimentation and flocculation. Subsequently, certain contaminants may still be present during the disinfection step of the drinking water treatment process.

Ozonation is a promising and environmentally compatible oxidation process. It is favorable for use in drinking water disinfection for its ability to degrade various recalcitrant organic pollutants through the direct use of ozone $\left(\mathrm{O}_{3}, E=\right.$ $2.07 \mathrm{~V})$ and indirect use of hydroxyl radicals $(\cdot \mathrm{OH}, E=2.8 \mathrm{~V}) .{ }^{8-10}$ Several studies have revealed that ozone shows great capacity in decomposing PPCPs. ${ }^{\mathbf{1 1 - 1 3}}$ To the best of our knowledge, information regarding ketoprofen being efficiently eliminated by the ozonation process in pure water has been long known for a long time. ${ }^{\mathbf{1 4 , 1 5}}$ However, until now, detailed research pertaining to the degradation of target pollutants under the repercussions of coexisting ions has been negligible.

Inorganic nitrogen (including primarily nitrate, nitrite, and ammonium ions) has been frequently detected in both surface and groundwaters at concentrations of $10^{-6}$ to $10^{-3} \mathrm{M} \cdot{ }^{16,17}$ Over the last few years, inorganic nitrogen has been extensively studied, and it has been proven that these nitrogen-containing ions may produce hydroxyl radicals and other reactive groups, thereby promoting or restraining the oxidation of dissolved
School of Environmental Science and Engineering, Guangdong University Technology, No. 100 Waihuan Xi Road, Guangzhou Higher Education Mega Center, Panyu District, Guangzhou 510006, China.E-mail: liugg615@163.com

${ }^{b}$ School of Environment and Chemical Engineering, Foshan University, Guangdong 528000, China

'School of Environment, Tsinghua University, Beijing 100084, China

${ }^{d}$ School of Environmental Science and Engineering, Sun Yat-Sen University, Guangzhou 510275, China

$\dagger$ The first two authors contributed equally to this work. 
organic pollutants. ${ }^{18,19}$ As a matter of fact, $\mathrm{NO}_{3}{ }^{-}$has been considered as an environmental impact factor instead of a major research object in most studies..$^{\mathbf{2 0 2 1}}$ Thus, it is critically important to investigate the impact of $\mathrm{NO}_{3}{ }^{-}$on ketoprofen degradation by ozone during the drinking water disinfection process.

Given the lack of data and knowledge in this field, the goals of this study were to (1) technically evaluate the influence of $\mathrm{NO}_{3}{ }^{-}$toward the removal of ketoprofen by ozone under simulated water disinfection conditions including an elucidation of both the reaction kinetics and overall mechanism; (2) identify the disinfection by-products of KET with $\mathrm{NO}_{3}{ }^{-}$present in the system, presuming a tentative degradation pathway for KET during the process; (3) simply evaluate the toxicity of the byproducts with the employment of Chlorella and D. magna.

\section{Materials and methods}

\subsection{Reagents}

Ketoprofen, (KET, 2-(3-benzoylphenyl) propionic acid (purity $\geq$ 98\%) ) and ibuprofen were both purchased from TCI Reagent Co. Ltd. (Shanghai, China). Acetonitrile of HPLC-grade was purchased from U. S. ACS Enke Chemistry Co. Ltd. (Guangzhou, China). Benzoic acid was obtained from Aladdin Industrial Co. Ltd. (Shanghai, China). Other reagents employed in this study (e.g., sodium nitrate, sodium nitrite, ammonium sulfate, sulfuric acid, sodium hydroxide, and acetic acid) were all of analytical grade and were used without further purification. These reagents were obtained from the Guangzhou Chemical Reagent Factory. Ultrapure water (18.25 $\left.\mathrm{M} \Omega \mathrm{cm}^{-1}\right)$, obtained from a Milli-Q apparatus (Smart2 Pure ultrapure water/water system integration, TKA, Germany), was used in the preparation of all aqueous solutions during the experiment.

\subsection{Experimental apparatus and procedures}

$500 \mathrm{~mL}$ of $20 \mu \mathrm{mol} \mathrm{L}{ }^{-1} \mathrm{KET}$ solution was prepared, and the initial $\mathrm{pH}$ values were adjusted by $\mathrm{NaOH}$ or $\mathrm{H}_{2} \mathrm{SO}_{4}$ solution to keep the initial $\mathrm{pH}$ of each sample consistent and to reduce the experimental error. As shown in Fig. 1, the reactions were initiated by the introduction of ozone gas from an ozone generator (Quanju Technology, China), after which the gas was passed into an ozone concentration detector (UT-500, Adel Measurement and Control Technology Co., LTD, USA) where the ozone content in mixed gas was determined to be

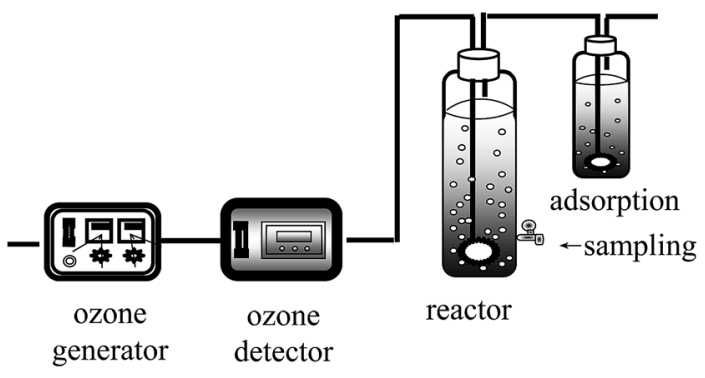

Fig. 1 Reaction equipment.
$16 \mu \mathrm{mol} \mathrm{L}{ }^{-1}$. Degradation experiments were conducted with laboratory-fabricated glass equipment (Fig. 1) using a gas dispersing device with a tap at the bottom. Ultimately, the unused portion of the gas mixture was absorbed by the potassium iodide solution.

\subsection{Analytical methods}

During the course of the experiments, $1.5 \mathrm{~mL}$ volumes of reaction liquid were incrementally extracted from the tap at 2, 4, 8, 12,16 , and $24 \mathrm{~min}$. The samples were immediately analyzed via the reversed-phase high-performance liquid chromatography system (Waters, USA), which was equipped with a Zorbax Eclipse XDB-C18 column $(4.6 \times 150$ mm, $5 \mu \mathrm{m}$, Agilent, USA). The analytical column temperature was $40{ }^{\circ} \mathrm{C}$, and $45 \%$ HPLCgrade acetonitrile and 55\% Milli-Q-Water (containing $0.5 \%$ glacial acetic acid) were used as the mobile phase at a constant flow rate of $1.0 \mathrm{~mL} \mathrm{~min}^{-1}$. The injection volume was $10 \mu \mathrm{L}$, and the UV wavelength for detection was $260 \mathrm{~nm}$. The elution time of KET was approximately $9.0 \mathrm{~min}$.

The KET degradation by-products were determined with the UPLC-Q-TOF-MS microsystem (Waters, USA) under chromatographic conditions (Table 1). The chromatographic column was introduced into a UV-vis detector equipped with an electrospray ionization (ESI) interface and mass analyzer, and the experiment was performed using a Waters TQ detector. The electrospray source voltages were as follows: capillary $(3.0 \mathrm{kV})$, sample cone $(30 \mathrm{~V})$, and extraction cone $(4.0 \mathrm{~V})$ under negative mode. The source block and desolvation gas were heated at 100 and $300{ }^{\circ} \mathrm{C}$, respectively. The concentrations of $\mathrm{NO}_{3}{ }^{-}$were determined by ion chromatography ( 882 , Metrohm AG, Switzerland).

\section{Results and discussion}

\subsection{Ozonation performance: ketoprofen influenced by $\mathrm{NO}_{3}{ }^{-}$}

As displayed in Fig. 2, the degradation of ketoprofen fitted pseudo first-order kinetics well. The degradation rate constants were $3.0 \times 10^{-2}, 3.6 \times 10^{-2}, 4.2 \times 10^{-2}$ and $4.6 \times 10^{-2} \mathrm{~min}^{-1}$ when the concentrations of $\mathrm{NO}_{3}{ }^{-}$were $0,0.01,0.1$, and $1 \mathrm{mmol} \mathrm{L}^{-1}$, respectively; the corresponding percentages $(\eta)$ were calculated to be $53 \%, 58 \%, 64 \%$, and $70 \%$. The results indicated that ketoprofen reacted effectively with $\mathrm{O}_{3}$, and more than half of the ketoprofen used for this study was degraded within $24 \mathrm{~min}$. It could be inferred that further degradation might be achieved with the prolongation of the reaction time. It was observed that $\mathrm{NO}_{3}{ }^{-}$ could accelerate the ozonation of ketoprofen, and as the concentration of $\mathrm{NO}_{3}{ }^{-}$was increased, a stronger effect was

Table 1 Chromatographic conditions

\begin{tabular}{llll}
\hline Time $(\mathrm{min})$ & Flow $\left(\mathrm{mL} \mathrm{min}^{-1}\right)$ & $A \%$ & $B \%$ \\
\hline 0 & 0.3 & 95 & 5 \\
6 & 0.3 & 80 & 20 \\
13 & 0.3 & 0 & 100 \\
14 & 0.3 & 95 & 5 \\
16 & 0.3 & 95 & 5
\end{tabular}




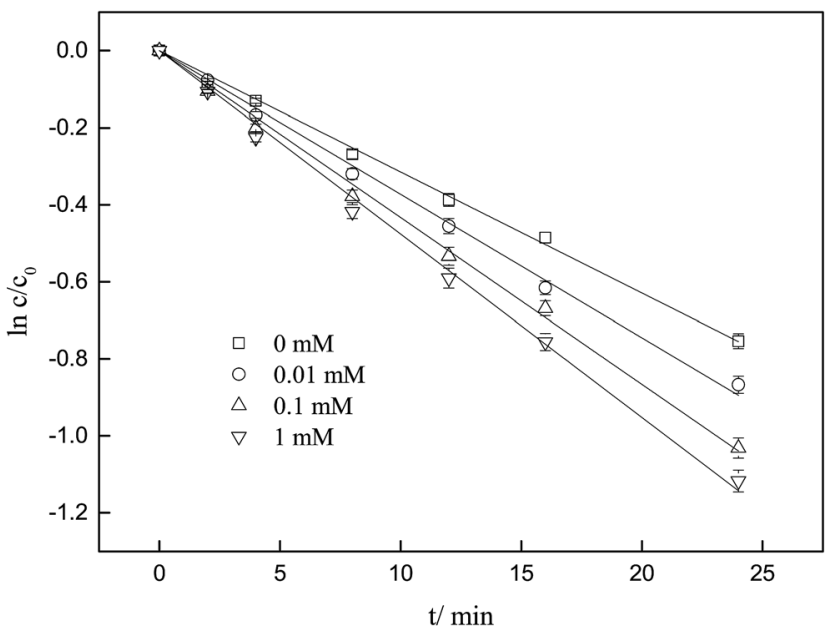

Fig. 2 Influence of $\mathrm{NO}_{3}{ }^{-}$on ozonation of KET.

elicited. The same phenomenon occurred when Miao investigated the effect of $\mathrm{NO}_{3}{ }^{-}$on the ozonation of phenazone. ${ }^{22}$

Typically, the degradation of organics by ozone is initiated through the combined activities of ozone molecules and hydroxyl radicals that are decomposed from $\mathrm{O}_{3} ;{ }^{23}$ the mechanism is illustrated in eqn (1) and (2). As previous studies have indicated, $\mathrm{NO}_{3}{ }^{-}$might induce the generation of $\cdot \mathrm{OH}$ to promote the degradation of organic matter in an oxidation system; ${ }^{18}$ the mechanism is articulated in eqn (3).

$$
\begin{gathered}
\mathrm{O}_{3}+\mathrm{OH}^{-} \rightarrow \mathrm{HO}_{2}^{-}+\mathrm{O}_{2} \\
\mathrm{O}_{3}+\mathrm{HO}_{2}{ }^{-} \rightarrow \cdot \mathrm{OH}+\mathrm{O}_{2}{ }^{--}+\mathrm{O}_{2} \\
\mathrm{NO}_{3}{ }^{-}+\mathrm{O}_{2}{ }^{--}+2 \mathrm{H}_{2} \mathrm{O} \rightarrow \cdot \mathrm{NO}_{3}+2 \cdot \mathrm{OH}+2 \mathrm{OH}^{-}
\end{gathered}
$$

To further explore the mechanism of influence of $\mathrm{NO}_{3}{ }^{-}$on the ozonation of ketoprofen, quenching experiments were conducted to identify the generation of $\cdot \mathrm{OH}$. tert-Butyl alcohol (TBA), a widely used $\cdot \mathrm{OH}$ scavenger in many quenching experiments, ${ }^{10,24,25}$ was selected to confirm the existence of $\cdot \mathrm{OH}$ in the system and to evaluate the contribution of $\cdot \mathrm{OH}$ to the degradation of ketoprofen in accordance with eqn (4). As exhibited in Table 2, TBA dramatically reduced the degradation of ketoprofen, which indicated that $\cdot \mathrm{OH}$ existed in the system and contributed to the degradation of ketoprofen, with the contribution rates of $90 \%, 80.56 \%, 76.19 \%$, and $73.91 \%$ when the concentrations of $\mathrm{NO}_{3}^{-}$were $0,0.01,0.1$, and $1 \mathrm{mmol} \mathrm{L}^{-1}$, respectively. Thus, it could preliminarily be determined that $\mathrm{NO}_{3}{ }^{-}$might induce the generation of $\cdot \mathrm{OH}$.

According to eqn (5), if the reaction rate constant between ketoprofen and $\cdot \mathrm{OH}$ was known, the steady-state concentration of $\cdot \mathrm{OH}$ in the system could be calculated. Therefore, a competitive experiment was conducted to obtain this constant. In this section, benzoic acid (BA) was selected as a probe in this competitive experiment to evaluate the reaction rate constant between ketoprofen and $\cdot \mathrm{OH}$. The initial concentration of both ketoprofen and benzoic acid was $20 \mu \mathrm{mol} \mathrm{L}^{-1}$, and the $\mathrm{pH}$ value was adjusted to 10 to ensure a sufficient quantity of $\cdot \mathrm{OH}$ as well as to neglect the degradation caused by $\mathrm{O}_{3}$. The degradation rate constants of ketoprofen and benzoic acid were $2.9 \times 10^{-2}$ and $1.9 \times 10^{-2} \mathrm{~min}^{-1}$, respectively.

It is known that the reaction rate constant between benzoic acid and $\cdot \mathrm{OH}$ is $5.9 \times 10^{9} \mathrm{M}^{-1} \mathrm{~S}^{-1},{ }^{26}$ according to eqn (5)-(7), and the reaction rate constant between ketoprofen and $\cdot \mathrm{OH}$ is calculated to be $8.82 \times 10^{9} \mathrm{M}^{-1} \mathrm{~S}^{-1}$, which coincided with results of previous research $\left(8.4 \times 10^{9} \mathrm{M}^{-1} \mathrm{~S}^{-1}\right) \cdot{ }^{15}$ Therefore, the steady state concentration of $\cdot \mathrm{OH}$ could be calculated from eqn (8). As evidenced in Table 2, the concentration of $\mathrm{NO}_{3}{ }^{-}$increased from 0 to $1 \mathrm{mmol} \mathrm{L}^{-1}$, and the steady state concentration of $\cdot \mathrm{OH}$ increased from $5.10 \times 10^{-11}$ to $6.42 \times 10^{-11} \mathrm{mmol} \mathrm{L}^{-1}$. These results affirmed that $\mathrm{NO}_{3}{ }^{-}$could induce the generation of $\cdot \mathrm{OH}$ and that the concentration of $\cdot \mathrm{OH}$ increased with higher $\mathrm{NO}_{3}{ }^{-}$ concentrations within a certain range $\left(0-1 \mathrm{mmol} \mathrm{L}^{-1}\right)$.

$$
\begin{gathered}
R_{\cdot \mathrm{OH}}=\frac{k \cdot \mathrm{OH}}{k_{\mathrm{obs}}} \approx \frac{k_{\mathrm{obs}}-k_{\mathrm{TBA}}}{k_{\mathrm{obs}}} \\
\ln \frac{[\mathrm{KET}]}{[\mathrm{KET}]_{0}}=k_{\mathrm{obs}} t=k \cdot \mathrm{OH}, \mathrm{KET}[\cdot \mathrm{OH}] t \\
\ln \frac{[\mathrm{BA}]}{[\mathrm{BA}]_{0}}=k_{\mathrm{BA}} t=k \cdot \mathrm{OH}, \mathrm{BA}[\cdot \mathrm{OH}] t \\
k \cdot \mathrm{OH}, \mathrm{KET}=\frac{k_{\mathrm{obs}}}{k_{\mathrm{BA}}} \cdot \mathrm{OH}, \mathrm{BA} \\
{[\cdot \mathrm{OH}]=\frac{k \cdot \mathrm{OH}}{k \cdot \mathrm{OH}, \mathrm{KET}}}
\end{gathered}
$$

\begin{tabular}{|c|c|c|c|c|c|c|}
\hline \multirow[b]{2}{*}{ Items } & \multirow[b]{2}{*}[\mathrm{NO}_{3}{}^{-}]{$(\mathrm{mM})$} & \multicolumn{2}{|c|}{$K_{\mathrm{obs}} \times 10^{-2} \mathrm{~min}^{-1}$} & \multirow[b]{2}{*}{$k \cdot \mathrm{OH}\left(\min ^{-1}\right)$} & \multirow[b]{2}{*}{$R \cdot \mathrm{OH}(\%)$} & \multirow{2}{*}{$\begin{array}{l}{[\cdot \mathrm{OH}]} \\
\left(10^{-11} \mathrm{mmol} \mathrm{L}^{-1}\right)\end{array}$} \\
\hline & & Without TBA & With TBA & & & \\
\hline 2 & 0.01 & $3.6 \pm 0.136$ & $0.7 \pm 0.0245$ & $2.9 \pm 0.1115$ & 80.56 & 5.48 \\
\hline 3 & 0.1 & $4.2 \pm 0.105$ & $1.0 \pm 0.0435$ & $3.2 \pm 0.0615$ & 76.19 & 6.05 \\
\hline 4 & 1 & $4.6 \pm 0.102$ & $1.2 \pm 0.0504$ & $3.4 \pm 0.0516$ & 73.91 & 6.42 \\
\hline
\end{tabular}

here, $R_{\mathrm{OHH}_{\mathrm{OH}}}$ is the contribution of $\cdot \mathrm{OH}, k_{\cdot \mathrm{OH}}$ is the degradation rate constant of ketoprofen with $\cdot \mathrm{OH}, k_{\mathrm{TBA}}$ is the degradation rate of ketoprofen with the existence of TBA in the system, $k_{\mathrm{BA}}$ represents the overall degradation rate of benzoic acid in the system, $[\mathrm{BA}]$ is the molar concentration of benzoic acid at a specified time, $k_{\text {-OH,KET }}$ and $k_{\text {. } \mathrm{OH, \textrm {BA }}}$ are the reaction rate

Table 2 Ketoprofen degradation kinetics, $k_{\mathrm{obs}}, k_{\mathrm{OH}}, R \cdot \mathrm{OH}$ and $[\cdot \mathrm{OH}]$ 
constants of $\cdot \mathrm{OH}$ with ketoprofen and benzoic acid, respectively, and $[\cdot \mathrm{OH}]$ represents the steady state concentration of $\cdot \mathrm{OH}$ in the system.

\subsection{By-products and degradation pathway speculation}

This section summarizes the content mentioned above with the aim of further investigating the ketoprofen degradation mechanism under the presence of $1 \mathrm{mM}$ nitrate ions as well as the identification of all degradation by-products.

The ketoprofen degradation products were analyzed by UPLC-Q-TOF-MS using the ESI negative ion mode, which allowed for the identification of a total of six compounds including the unaltered parent ketoprofen and five intermediates. The complete ion chromatograms are depicted in Fig. 3, with five major degradation by-product peaks at 1.68, 2.67, 5.00, 5.92, and 8.29 min assigned to P1, P2, P3, P4, and P5, respectively. Mass spectra and mass characteristics (e.g., retention time, $\mathrm{m} / \mathrm{z}$, fragments, and prediction formula) of the abovementioned substances are summarized in Table 3, whereas fragment chart analyses of the secondary ion mass spectrometry of the P1-P5 photolysis products are displayed in Fig. 4. Overall, the degradation of ketoprofen appeared to have at least four pathways: (1) hydroxylation on benzene ring pathway, (2) nitration on benzene ring pathway, (3) debenzophenone pathway, (4) ketonized pathway.

Due to the cogent electron-withdrawing effect of the carboxylic acid group and benzophenone group in the ketoprofen structure, the oxidation reaction preferentially occurred at the phenyl ring I rather than II. In addition, the metapositions were easily activated and were vulnerable to attack, and this resulted in the formation of meta-by-products. ${ }^{27}$

On one hand, the formula of $\mathrm{P} 2$ is $\mathrm{C}_{16} \mathrm{H}_{14} \mathrm{O}_{4}$, and the $\mathrm{m} / z$ was 270 with an additional $\mathrm{O}$ compared to those of the parents; major fragments at $m / z 253(-16), 225(-44)$, and 209(-60) might correspond to the observed $-\mathrm{OH}$ loss, $-\mathrm{COOH}$ loss and the loss of both, respectively. These results resulted in the assumption that P6 was a monohydric derivative compound of ketoprofen degradation, which was formed from an electrophilic substitution $(\mathrm{H}$ by $\cdot \mathrm{OH})$ on the aromatic ring. The mechanism of hydroxylation in ozonation is illustrated in Fig. 5 including the electrophilic substitution by $\mathrm{O}_{3}$ or nucleophilic attack by $\cdot \mathrm{OH} .^{28}$ Thus, Section 3.1 indicated that $\cdot \mathrm{OH}$ had a much higher contribution rate on the degradation of ketoprofen than $\mathrm{O}_{3}$ did. Thus, the nucleophilic substitution of $\cdot \mathrm{OH}$ in the benzene ring was inferred to be the dominant mechanism of benzene hydroxylation. As Illés ${ }^{29}$ mentioned in his study of the photoinduced degradation of ketoprofen in pure water, the hydroxylation by-products formed during the degradation of ketoprofen were preferentially due to the attack of $\cdot \mathrm{OH}$ on the benzene ring.

Furthermore, P5 $\left(\mathrm{C}_{16} \mathrm{H}_{13} \mathrm{NO}_{5}, m / z 299\right)$ in the $\mathrm{MS}^{2}$ fragmentation spectrum of $\mathrm{m} / \mathrm{z} 298$ and the major fragments at $\mathrm{m} / \mathrm{z} 252$ $(-46)$ and $254(-44)$ might correspond to the loss of $-\mathrm{NO}_{2}$ and $-\mathrm{COOH}$. However, $\cdot \mathrm{NO}_{2}$ was generated according to eqn (2). The delocalization of a positive charge from $\cdot \mathrm{NO}_{2}$ to the aromatic ring brought about a strong electron-deficiency in the metapositions on the aromatic ring, ${ }^{30}$ with a nitration-derivative of ketoprofen.

Apart from the two above-mentioned pathways, P4 (phenylpropionic acid, $\mathrm{C}_{9} \mathrm{H}_{10} \mathrm{O}_{2}, m / z$ 149) was analyzed by UPLC-Q-TOFMS at a retention time of $5.92 \mathrm{~min}$, and it was defined as a byproduct of ketoprofen debenzophenone pathway. Previous investigations were supportive of this pathway during the advanced oxidation of benzophenone-3..$^{31,32}$ Subsequently, P3 compounds (ortho-hydroxybenzene propanoic acid, $\mathrm{C}_{9} \mathrm{H}_{10} \mathrm{O}_{3}, \mathrm{~m} / \mathrm{z}$ 166) were determined to be hydroxylated intermediates of $\mathrm{P} 4$ formed by undergoing further attacks on the meta-position of the benzene ring. Moreover, the $-\mathrm{COOH}$ group on the side-chain of $\mathrm{P} 3$ was observed to be further oxidized to form $\mathrm{P} 1\left(\mathrm{C}_{8} \mathrm{H}_{8} \mathrm{O}_{2}, \mathrm{~m} / z\right.$ 136).

\subsection{Toxicity measurement}

Toxicity measurement of organic pollutants is an essential indicator for practical wastewater treatment. As shown in Fig. 6, the initial immobilization rates of D. magna were $26.72 \%$ and $61.44 \%$ at $24 \mathrm{~h}$ and $48 \mathrm{~h}$ exposure, respectively. During the ozonation process, the immobilization rate was reduced slightly during treatment for $4 \mathrm{~min}$. However, an evident increment occurred as the treatment proceeded and reached up to $50 \%$ and ultimately $80.56 \%$. A similar trend was observed in the assay of algae, suggesting that the decomposition of initial KET led to the decrease of immobilization rate at the beginning. The accumulation of by-products resulted in the constant increase in the immobilization rate, indicating that the ecological risks of ozonation process are worthy of attention in practical treatment.

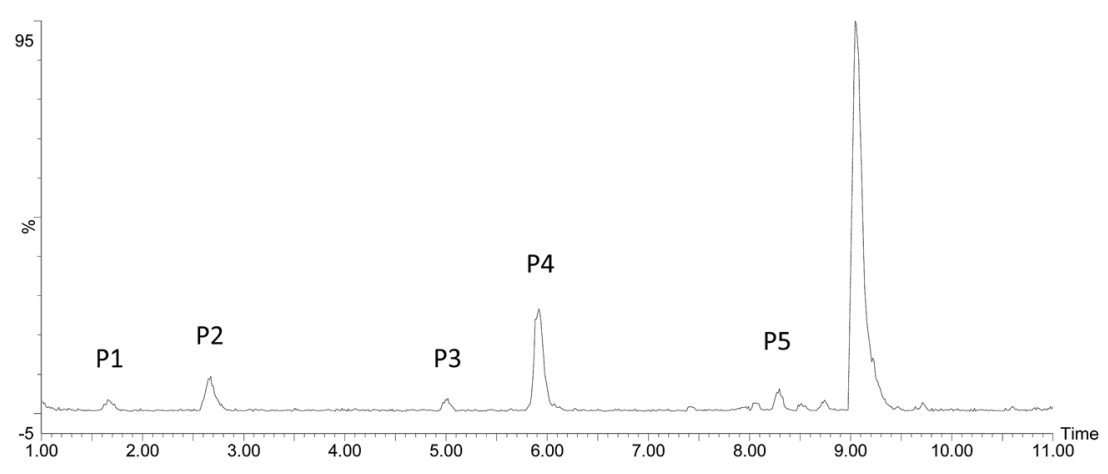

Fig. 3 The total ion current of oxidation by-products. 
Table 3 Mass data obtained from the UPLC/MS/MS of ketoprofen oxidation by-products

\begin{tabular}{|c|c|c|c|c|c|}
\hline Peak & $\begin{array}{l}\text { Retention time } \\
\text { (min) }\end{array}$ & ESI(-)MW & $\mathrm{mDa}$ & Fragments of $\mathrm{MS}^{2}$ & Prediction formula \\
\hline P1 & 1.68 & $136.1464[\mathrm{M}-\mathrm{H}]^{-}$ & -3.5 & $135,119,94$ & $\mathrm{C}_{8} \mathrm{H}_{8} \mathrm{O}_{2}$ \\
\hline P3 & 5.00 & $165.1732[\mathrm{M}-\mathrm{H}]^{-}$ & 2.8 & $165,149,121$ & $\mathrm{C}_{9} \mathrm{H}_{10} \mathrm{O}_{3}$ \\
\hline $\mathrm{P} 4$ & 5.92 & $149.1746[\mathrm{M}-\mathrm{H}]^{-}$ & 2.4 & 149,105 & $\mathrm{C}_{9} \mathrm{H}_{10} \mathrm{O}_{2}$ \\
\hline P5 & 7.41 & $298.2833[\mathrm{M}-\mathrm{H}]^{-}$ & -0.3 & $298,252,254$ & $\mathrm{C}_{16} \mathrm{H}_{13} \mathrm{NO}_{5}$ \\
\hline
\end{tabular}
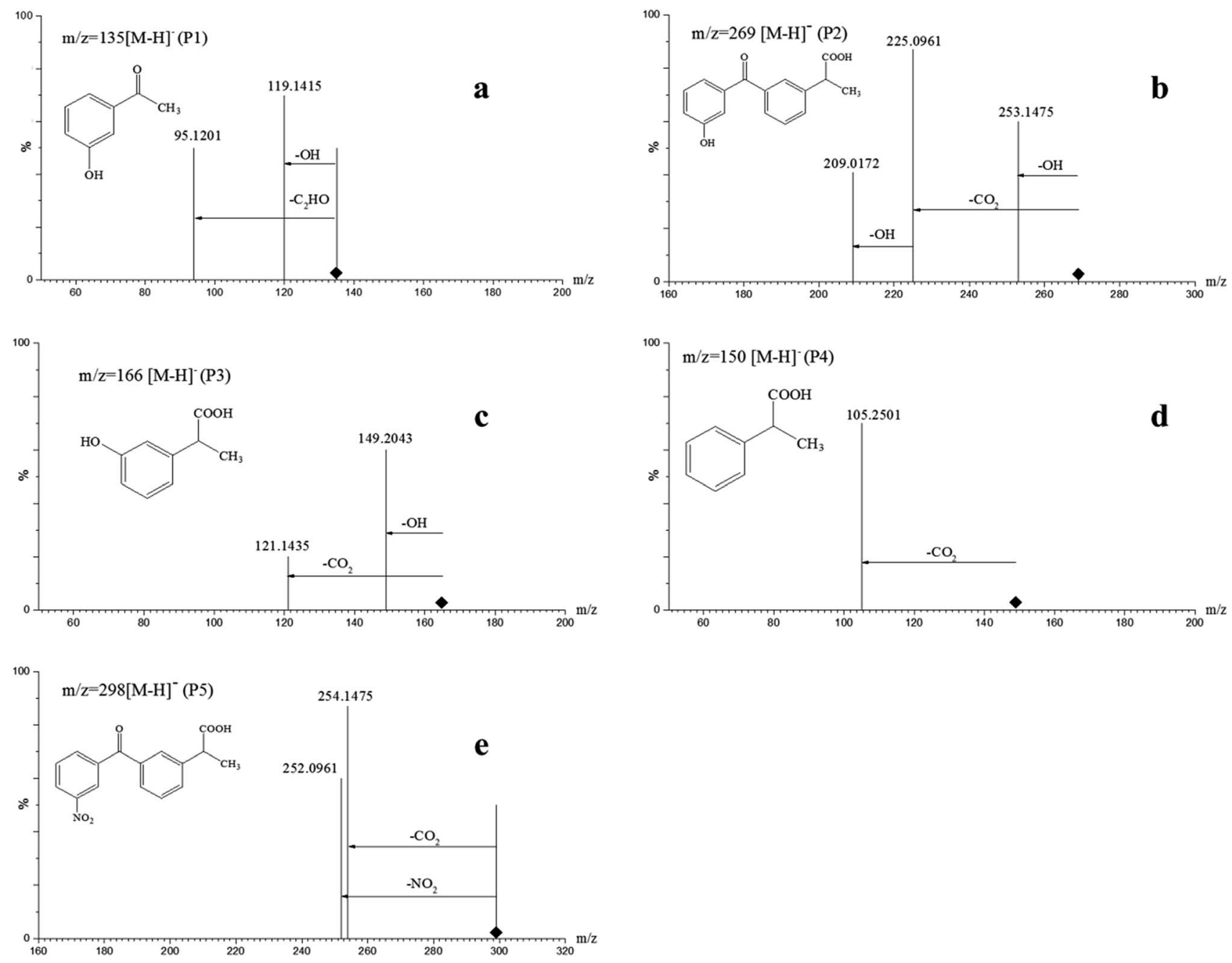

Fig. 4 Fragment chart analyses of the secondary ion mass spectrometry of P1-P5.

\subsection{Ozonation of ketoprofen influenced by $\mathrm{NO}_{2}{ }^{-}$and $\mathrm{NH}_{4}{ }^{+}$}

It was revealed in Fig. 7 and Table 4 that $\mathrm{NH}_{4}{ }^{+}$also had the capacity to accelerate the degradation of ketoprofen, which was similar to that of $\mathrm{NO}_{3}{ }^{-}$, but this capacity was less aggressive. On the contrary, $\mathrm{NO}_{2}{ }^{-}$showed inhibitory effect in the degradation of ketoprofen, in that, as the $\mathrm{NO}_{2}{ }^{-}$concentration increased, a stronger inhibition would occur. It was reported that the existence of $\mathrm{NO}_{2}{ }^{-}$negatively affected the degradation of organic matter by AOPs. ${ }^{18}$

As for $\mathrm{NH}_{4}{ }^{+}$, previous studies have suggested that ozone might transform $\mathrm{NH}_{4}{ }^{+}$to $\mathrm{NO}_{3}{ }^{-}$via the strong oxidizing capacity that directly converted $\mathrm{N}(-3)$ into $\mathrm{N}(+5)$ as revealed in eqn (9),,$^{33-35}$ thereby facilitating the degradation of organic matter in the same manner as that with $\mathrm{NO}_{3}{ }^{-}$.

$$
\mathrm{NH}_{4}{ }^{+}+4 \mathrm{O}_{3} \rightarrow \mathrm{NO}_{3}{ }^{-}+2 \mathrm{H}^{+}+\mathrm{H}_{2} \mathrm{O}+4 \mathrm{O}_{2}
$$

$\mathrm{NO}_{2}{ }^{-}$comprises a type of reductive substance that has the capacity to perform redox reactions with substances in oxidation systems. This mechanism is elucidated in eqn (10) and (11), where the reaction rate constant between $\mathrm{NO}_{2}{ }^{-}$and ozone molecules is $2.27 \times 10^{7} \mathrm{M}^{-1} \mathrm{~S}^{-1} \cdot{ }^{36}$ According to eqn (12)-(14), 


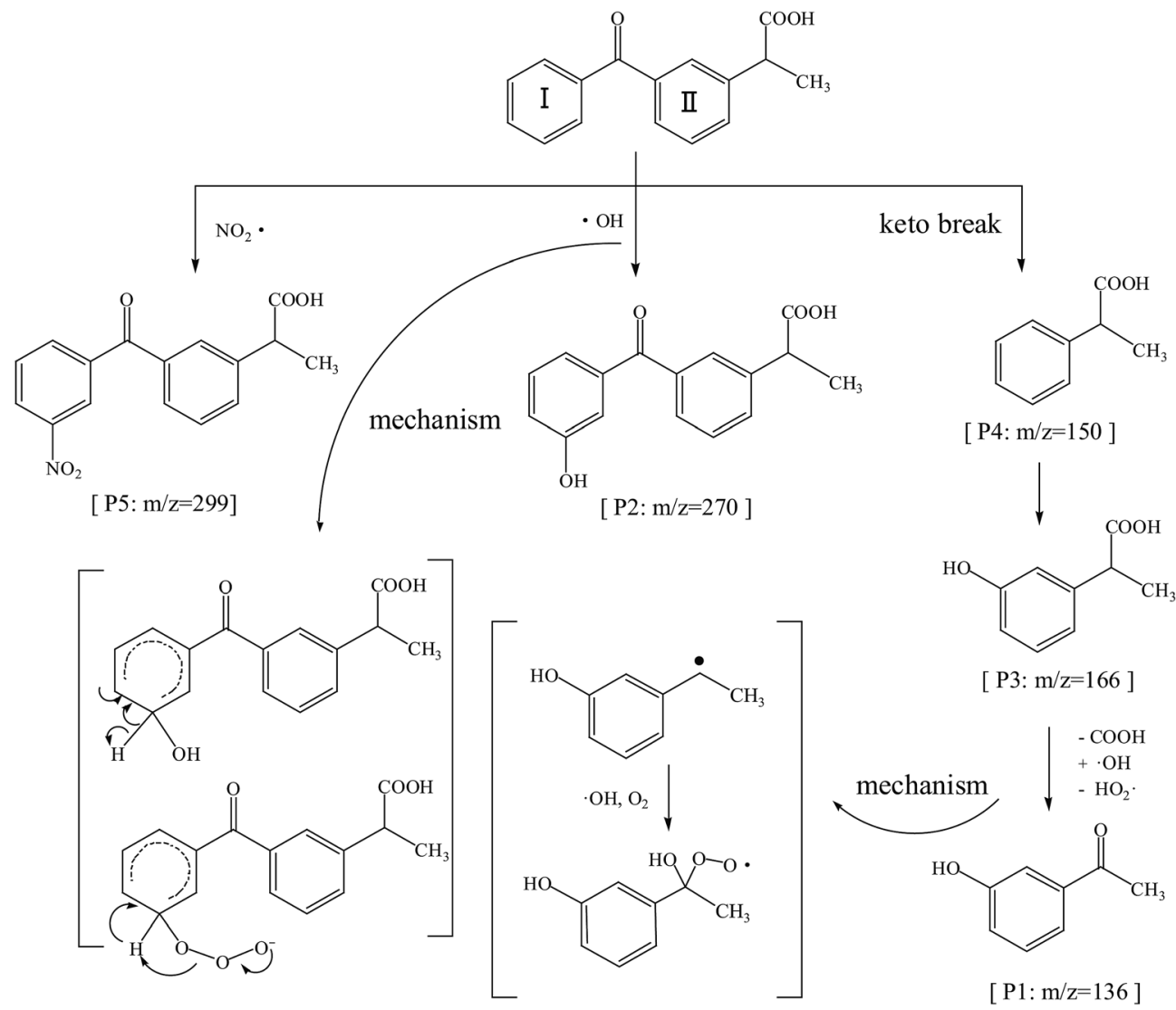

Fig. 5 Possible oxidation pathways of KET in nitrate aqueous solution.

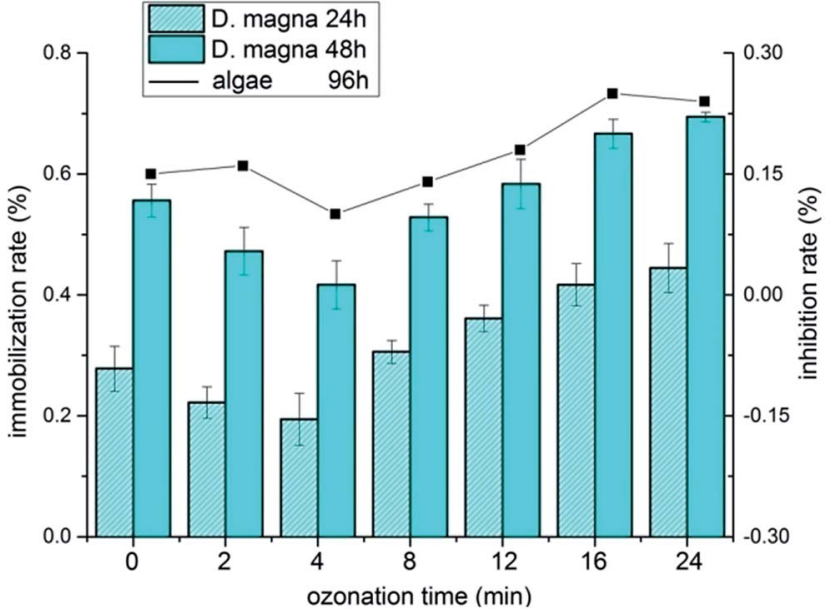

Fig. 6 Variation of immobilization rates of D. magna in $24 \mathrm{~h}$ and $48 \mathrm{~h}$ (rectangle) and inhibition rate of algae in $96 \mathrm{~h}$ (line).

the reaction rate constant between ketoprofen and $\mathrm{O}_{3}$ can be elucidated through competitive experiments using ibuprofen (IBP) as a probe. During the experiments, the initial concentrations of both ketoprofen and ibuprofen are $20 \mu \mathrm{mol} \mathrm{L}{ }^{-1}$, and the degradation initiated by $\cdot \mathrm{OH}$ can be ignored via the addition of excess TBA and the adjustment of the $\mathrm{pH}$ value to 2 . The degradation rate constant of ketoprofen is $0.5 \times 10^{-2} \mathrm{~min}^{-1}$,

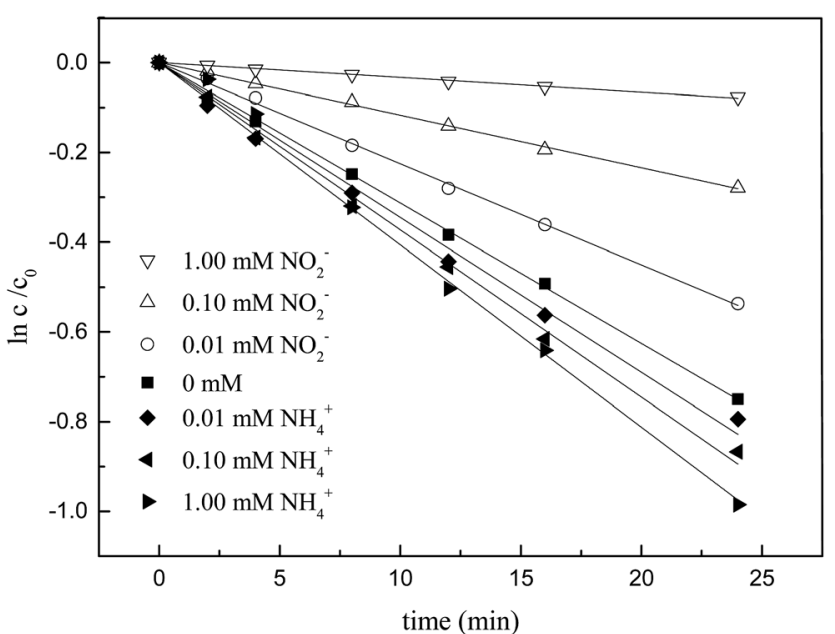

Fig. 7 Effect of different concentrations of $\mathrm{NO}_{2}{ }^{-}$and $\mathrm{NH}_{4}{ }^{+}$on ozonation of KET.

whereas it is $3.3 \times 10^{-2} \mathrm{~min}^{-1}$ for ibuprofen. It is known that the reaction rate constant between IBP and $\mathrm{O}_{3}$ is $7.2 \mathrm{M}^{-1} \mathrm{~S}^{-1},{ }^{37}$ and the reaction rate constant between ketoprofen and $\mathrm{O}_{3}$ is $1.09 \mathrm{M}^{-1} \mathrm{~S}^{-1}$.

$$
\mathrm{NO}_{2}{ }^{-}+\mathrm{O}_{3} \rightarrow \mathrm{NO}_{3}{ }^{-}+\mathrm{O}_{2} 2.27 \times 10^{7} \mathrm{M}^{-1} \mathrm{~S}^{-1}
$$


Table 4 Reaction rate of different concentration of $\mathrm{NO}_{2}{ }^{-}$and $\mathrm{NH}_{4}{ }^{+}$

\begin{tabular}{llllllll}
\hline Species & \multicolumn{3}{c}{$\mathrm{NO}_{2}{ }^{-}$} & & $\mathrm{NH}_{4}{ }^{+}$ \\
\hline Concentration $(\mathrm{mM})$ & 0.00 & 0.01 & 0.10 & 1.00 & 0.00 & 0.01 & 0.10 \\
Reaction rate $\left(\times 10^{-2}\right)$ & 3.0 & 2.2 & 1.1 & 0.3 & 3.0 & 3.3 & 3.7
\end{tabular}

$$
\begin{gathered}
\mathrm{NO}_{2}^{-}+\cdot \mathrm{OH} \rightarrow \mathrm{NO}_{2} \cdot+\mathrm{OH}^{-}(1-10) \times 10^{9} \mathrm{M}^{-1} \mathrm{~S}^{-1} \\
\ln \frac{[\mathrm{KET}]}{[\mathrm{KET}]_{0}}=k_{\mathrm{obs}} t=k_{\mathrm{O}_{3}, \mathrm{KET}}\left[\mathrm{O}_{3}\right] t \\
\ln \frac{[\mathrm{IBP}]}{[\mathrm{IBP}]_{0}}=k_{\mathrm{IBP}} t=k_{\mathrm{O}_{3}, \mathrm{IBP}}\left[\mathrm{O}_{3}\right] t \\
k_{\mathrm{O}_{3}, \mathrm{KET}}=\frac{k_{\mathrm{obs}}}{k_{\mathrm{IBP}}} k_{\mathrm{O}_{3}, \mathrm{IBP}}
\end{gathered}
$$

here, $k_{\cdot \mathrm{O}_{3}, \mathrm{KET}}$ and $k_{\cdot \mathrm{O}_{3}, \mathrm{BA}}$ are the reaction rate constants of $\mathrm{O}_{3}$ with ketoprofen and benzoic acid, respectively.

In comparison, the reaction rate of ozone molecules with $\mathrm{NO}_{2}{ }^{-}\left(2.27 \times 10^{7} \mathrm{M}^{-1} \mathrm{~S}^{-1}\right)$ was much more rapid than that with ketoprofen (1.09 $\mathrm{M}^{-1} \mathrm{~S}^{-1}$ ). In this way, $\mathrm{NO}_{2}{ }^{-}$restrained the ozonation of ketoprofen as the ozone molecule scavenger. On the other hand, both $\mathrm{NO}_{2}{ }^{-}$and ketoprofen exhibited high reactive activities with $\cdot \mathrm{OH}$, with reaction rate constants between (1-10) $\times 10^{9} \cdot .^{17,19,38}$ The competition for $\cdot \mathrm{OH}$ between $\mathrm{NO}_{2}{ }^{-}$and KET directly led to the decrease of the degradation rate of ketoprofen. As mentioned in Section 3.1, the contribution of $\cdot \mathrm{OH}$ to ketoprofen was approximately $90 \%$, whereas the contribution of $\cdot \mathrm{OH}$ to ozone it was $10 \%$. In this way, the competition for $\cdot \mathrm{OH}$ between $\mathrm{NO}_{2}{ }^{-}$and KET was considered as the dominant factor in the reduction of the ketoprofen degradation rate.

\section{Conclusions}

The reaction kinetics and influence of different nitrogenous species on the ozonation of ketoprofen were investigated under simulated water disinfection conditions. Distinct discoveries demonstrated that the ketoprofen ozonation reactions aligned well with the pseudo first-order kinetics in the presence of $\mathrm{NO}_{3}{ }^{-}$. Five intermediates were simultaneously identified during the ozonation of ketoprofen, and four types of reaction pathways were speculated: hydroxylation and nitration on benzene ring, keto break, and ketonized reactions on the side chains. Furthermore, toxicity evaluation revealed that more harmful by-products were generated, which suggested that more attention should be paid to the wastewater disinfection process. Additionally, the experiment of $\mathrm{NO}_{2}{ }^{-}$and $\mathrm{NH}_{4}{ }^{+}$simply implied that the presence of nitrogenous species could influence the ozonation of ketoprofen.

\section{Conflicts of interest}

There are no conflicts to declare.

\section{Acknowledgements}

This study is supported by the National Natural Science Foundation of China (No. 21377031 and 21677040) and the Science and Technology Planning Project of Guangdong Province (No. 2017A050506052). The authors would like to thank all the editors and reviewers for their aid in the improvement of this paper.

\section{Notes and references}

1 L. P. Padhye, H. Yao, F. T. Kung'U and C. H. Huang, Water Res., 2014, 51, 266-276.

2 P. Verlicchi, A. M. Al and E. Zambello, Sci. Total Environ., 2012, 429, 123.

3 K. A. K. Musa, J. M. Matxain and L. A. Eriksson, J. Med. Chem., 2007, 50, 1735-1743.

4 J. L. Santos, I. Aparicio and E. Alonso, Environ. Int., 2007, 33, 596-601.

5 J. L. Cao, J. H. Shi, R. Han, Y. X. Li and Z. F. Yang, Chin. Sci. Bull., 2010, 55, 3138-3144.

6 B. Kasprzyk-Hordern, R. M. Dinsdale and A. J. Guwy, Water Res., 2008, 42, 3498-3518.

7 V. D. A. Ng, G. J. Kommer, J. E. van Montfoort and J. F. Versteegh, Water Sci. Technol., 2011, 63, 825-831.

8 P. Gagoferrero, K. Demeestere, D. M. Silvia and D. Barceló, Sci. Total Environ., 2013, 443, 209-217.

9 R. Broséus, S. Vincent, K. Aboulfadl, A. Daneshvar, S. Sauvé, B. Barbeau and M. Prévost, Water Res., 2009, 43, 4707-4717.

10 W. B. De, J. Dewulf, K. Demeestere and L. H. Van, J. Hazard. Mater., 2009, 161, 701.

11 I. Zucker, Y. Lester, D. Avisar, U. Hübner, M. Jekel, Y. Weinberger and H. Mamane, Environ. Sci. Technol., 2015, 49, 301-308.

12 M. G. Antoniou, G. Hey, S. R. Vega, A. Spiliotopoulou, J. Fick, M. Tysklind, J. L. C. Jansen and H. R. Andersen, Sci. Total Environ., 2013, 456-457, 42-49.

13 M. M. Gómez-Ramos, M. Mezcua, A. Agüera, A. R. Fernández-Alba, S. Gonzalo, A. Rodríguez and R. Rosal, J. Hazard. Mater., 2011, 192, 18.

14 E. Illés, E. Szabó, E. Takács, L. Wojnárovits, A. Dombi and K. Gajdaschrantz, Sci. Total Environ., 2014, 472, 178-184.

15 F. J. Real, F. J. Benitez, J. L. Acero, J. J. P. Sagasti and F. Casas, Ind. Eng. Chem. Res., 2009, 48, 3380-3388.

16 M. V. Shankar, S. Nélieu, L. Kerhoas and J. Einhorn, Chemosphere, 2008, 71, 1461-1468.

17 M. V. Shankar, S. Nélieu, L. Kerhoas and J. Einhorn, Chemosphere, 2007, 66, 767.

18 Y. Wang, H. Liu, G. Liu, Y. Xie and T. Ni, Environ. Sci. Pollut. Res., 2015, 22, 9449-9456.

19 J. Mack and J. R. Bolton, J. Photochem. Photobiol., A, 1999, 128, 1-13.

20 Y. Feng, Q. Song, W. Lv and G. Liu, Chemosphere, 2017, 189, 643-651. 
21 T. Yang, J. Peng, Y. Zheng, X. He, Y. Hou, L. Wu, X. Fu, T. Yang, J. Peng and Y. Zheng, Appl. Catal., B, 2017, 221.

22 H. F. Miao, M. Cao, D. Y. Xu, H. Y. Ren, M. X. Zhao, Z. X. Huang and W. Q. Ruan, Chemosphere, 2015, 119, 326333.

23 U. V. Gunten, Water Res., 2003, 37, 1443-1467.

24 C. Jing, W. Gang, T. Huang, L. Deng and J. Ma, Chem. Eng. J., 2015, 264, 399-403.

25 M. M. Sein, M. Zedda, J. Tuerk, T. C. Schmidt, A. Golloch and C. V. Sonntag, Environ. Sci. Technol., 2008, 42, 6656-6662.

26 Y. Ji, L. Zhou, Y. Zhang, C. Ferronato, M. Brigante, G. Mailhot, X. Yang and J. M. Chovelon, Water Res., 2013, 47, 5865-5875.

27 K. S. Tay, N. A. Rahman and M. R. B. Abas, Microchem. J., 2011, 99, 312-326.

28 J. Kuang, J. Huang, B. Wang, Q. Cao, S. Deng and G. Yu, Water Res., 2013, 47, 2863-2872.

29 E. Illés, E. Takács, A. Dombi, K. Gajda-Schrantz, K. Gonter and L. Wojnárovits, Radiat. Phys. Chem., 2012, 81, 14791483.
30 M. C. Dodd and C. H. Huang, Environ. Sci. Technol., 2004, 38, 5607-5615.

31 P. Gong, H. Yuan, P. Zhai, Y. Xue, H. Li, W. Dong and G. Mailhot, Chem. Eng. J., 2015, 277, 97-103.

32 T. Manasfi, V. Storck, S. Ravier, C. Demelas, B. Coulomb and J. L. Boudenne, Environ. Sci. Technol., 2015, 49, 9308-9316.

33 P. Rahmadi and Y. R. Kim, Desalin. Water Treat., 2014, 52, 4413-4422.

34 B. Ruffino and M. C. Zanetti, Desalin. Water Treat., 2012, 37, 130-138.

35 M. Yang, K. Uesugi and H. Myoga, Water Res., 1999, 33, 19111917.

36 R. E. Huie and J. T. Herron, Chem. Phys. Lett., 1974, 27, 411414.

37 N. K. Vel Leitner and B. Roshani, Water Res., 2010, 44, 2058. 38 G. V. Buxton, C. L. Greenstock, W. P. Helman and A. B. Ross, J. Phys. Chem. Ref. Data, 1988, 17, 513-886. 